\title{
O NATAL DOS SONHOS DELES: ANÁLISE DIALÓGICA DE UMA INTERVENÇÃO ARTÍSTICA URBANA
}

\author{
THE CHRISTMAS OF DREAMS: \\ DIALOGICAL ANALYSIS OF AN URBAN ARTISTIC INTERVENTION
}

\author{
Fernanda Dias de Los Rios Mendonça ${ }^{1}$ \\ Sue Anne Guimarães Cursino Pessoa ${ }^{2}$
}

\begin{abstract}
Resumo: Neste artigo, analisamos uma obra de arte produzida como contra-resposta à má administração do dinheiro público por representantes políticos de Parintins, cidade do interior do Amazonas. A análise apreendida subsidia-se nos aportes teórico-metodológicos do Círculo de Bakhtin, sobretudo, na perspectiva dialógica da linguagem. De acordo com essa diretriz epistemológica, o objeto de análise é tomado como enunciado concreto situado em uma esfera de atividade demarcada por uma construção inacabada e cujo resultado discursivo apresentase, simultaneamente, como obra artística e como resistência político-ideológica inserida na materialidade histórica dos contextos sociais imediato (Parintins) e mediatos (Amazônico e Brasileiro).
\end{abstract}

Palavras-chave: dialogismo; contra-resposta; arte; ideologia; Casa da Cultura de Parintins.

Abstract: In this article, we analyze a work of art produced as a counter-response to the mismanagement of public money by political representatives of Parintins, a city in the interior of the Amazon. The apprehended analysis is subsidized in the theoretical-methodological contributions of the Circle of Bakhtin, mainly, in the dialogical perspective of the language. According to this epistemological guideline, the object of analysis is taken as a concrete statement situated in a sphere of activity demarcated by an unfinished construction and whose discursive result presents itself both as an artistic work and as political-ideological resistance inserted in historical materiality of the immediate (Parintins) and mediate (Amazonian and Brazilian) social contexts.

Keywords: dialogism; against-response; art; ideology; House of Culture of Parintins.

\footnotetext{
${ }^{1}$ Doutora em Linguística pela Universidade Federal de Santa Catarina (2014), atualmente é professora adjunta na Faculdade de Letras da Universidade Federal do Amazonas, coordenadora do Programa de Iniciação à Docência - PIBID de Língua Portuguesa e líder do Grupo de Pesquisa em Linguística Aplicada e Discurso (LADI). Email: fernandadelosrios@yahoo.com.br

${ }^{2}$ Mestre pelo Programa de Mestrado em Sociedade e Cultura na Amazônia, da Universidade Federal do Amazonas (2017). E-mail: sueannegcursino@ hotmail.com
} 


\section{Introdução}

No contexto sócio histórico atual, as diferentes dimensões artísticas ganham primordial relevância na expressão dos sentimentos e reverberações políticas e ideológicas dos sujeitos. "Vivemos em uma civilização das imagens" (JOLY, 1996, p. 11). Seguindo a afirmação da autora, entendemos relevante a consideração das produções artísticas humanas dado que suas materialidades constituem expressões individuais ou coletivas representativas de determinados grupos sociais, bem como figuram enquanto intervenções que se impõem em determinado espaço-tempo social.

Nessa perspectiva, cabe a retomada do conceito latino Imago (imagem), entendido como produção comunicativa e cultural que pode representar algo real ou imaginário, sendo resultado de um determinado contexto, possuidor de autoria coletiva ou individual e passível de leitura por diversos interlocutores, podendo, assim, estabelecer "um diálogo de sentidos com outras referências culturais de caráter verbal e não-verbal. As imagens nos contam histórias, atualizam memórias, inventam vivências, imaginando a história" (CIAVATTA \& ALVES, 2004, p. 22).

Nesse artigo, apresentamos recorte de pesquisa mais ampla, com o intuito de focalizar uma das obras analisadas em um contexto artístico amazônico peculiar, a Casa da Cultura, em Parintins, Amazonas. O aporte teórico-metodológico utilizado para realização da análise aqui apreendida ancora-se na perspectiva dialógica bakhtiniana, segundo a qual a obra artística constitui-se enunciado e o pesquisador constitui-se interlocutor privilegiado a empreender esforços, por meio de uma postura responsiva ativa, a interpretar/compreender seu significado.

\section{Dialogismo e o Círculo de Bakhtin}

À compreensão do conceito de dialogismo, fundamental para a análise realizada neste estudo, faz-se imprescindível o entendimento do chamado Círculo de Bakhtin e da perspectiva dialógica aprofundada por um de seus membros, Mikhail Bakhtin, cujo nome intitula o grupo de pensadores russos de diferentes áreas reunidos em prol de uma inquietação comum: a linguagem.

[...] segundo o dialogismo bakhtiniano, como é conhecida a concepção de linguagem do Círculo, importa a linguagem enquanto produção de sentidos, concretizada e decorrente de relações dialógicas entre enunciados de sujeitos, no âmbito da comunicação discursiva e não enquanto objeto de um sistema fechado. Tal produção, 
por conseguinte, se dá no nível da interação verbal, entre subjetividades num contexto social[...] (MENDONÇA, 2014, p.20)

Conforme nos atesta a concepção de linguagem cunhada pelo Círculo, a perspectiva bakhtiniana corresponde a um viés filosófico. É a preocupação com a função ideológica, histórica e social da linguagem que une, em um mesmo grupo, pensadores de formações variadas cujo construto teórico de base marxista é empreendido por meio de uma perspectiva arquitetônica.

Esse olhar filosófico sobre a linguagem estipula que

As relações dialógicas são de índole específica: não podem ser reduzidas a relações meramente lógicas (ainda que dialéticas) nem meramente linguísticas (sintáticocomposicionais). Elas só são possíveis entre enunciados integrais de diferentes sujeitos do discurso [...] (BAKHTIN, 2010 [1979], p. 323. Grifos do autor)

Entendendo que a base de pensamento bakhtiniano é filosófica, compreendemos que o conceito de dialogismo não se estabelece a partir do conceito de diálogo tomado do senso comum, mas abrangendo um escopo maior para dar conta das interações entre sujeitos sociais, por meio das quais a linguagem se concretiza em enunciados verbais ou não verbais, sempre materializados de algum modo em um determinado gênero discursivo, inseridos em uma esfera social e em uma dimensão cronotópica específicas. Nesse contexto, tem-se que

\footnotetext{
Os sentidos, por sua vez, não nascem a esmo, mas de relações estabelecidas ideologicamente entre seres sociais, numa situação de interação verbal, portanto, seu entendimento deve passar pelo entendimento prévio das relações estabelecidas entre os sujeitos, das instâncias sociais em que esses sujeitos se enunciam e dos contextos sociais, imediato e mediato, em que se desenrolam a interlocução. (MENDONÇA, 2014, p.21)
}

Dialogismo abrange assim o "diálogo" em sentido metafórico, abarcando as relações dialógicas que se estabelecem entre os sujeitos em diferentes níveis: pela relação direta ou indireta dos sujeitos da enunciação e pelas vozes que atravessam seus enunciados. Ou seja, não se considera, nessa perspectiva, apenas a relação dos interlocutores que compõem uma dada situação de interação, mas os diferentes matizes e valorações que compõem esses enunciados, nem sempre de maneira harmônica.

Vale ressaltar que, para os estudos bakhtinianos, constituem enunciados não apenas os textos verbais, mas toda a forma de manifestação do pensamento humano, como as obras de artes, por exemplo. É nessa condição que a obra tomada para análise neste artigo é considerada, 
como texto (enunciado) de um sujeito localizado historicamente. Essa posição teórica traz implicações para o encaminhamento metodológico e para a análise da obra.

Como enunciado, não pode ser considerada isolada de seu enunciador e de seus interlocutores diretos ou previstos; por outro lado, pelo encaminhamento metodológico derivado da proposta bakhtiniana, pressupõe-se a análise de sua inserção contextual prévia, a fim de apreender os sentidos ideológicos acionados, as valorações emergentes e os significados produzidos.

Por essa razão, dedicamo-nos, na sequência, a explicitar algumas nuances necessárias da perspectiva de pesquisa sob a ótica de Bakhtin.

\section{Pesquisa em Ciências Humanas}

Nos textos $O$ problema do texto na linguística, na filologia e em outras ciências humanas e Metodologia das ciências humanas, Bakhtin trata da temática da pesquisa nas áreas de Humanas. Segundo o pensador russo, o objeto de pesquisa das ciências humanas é o texto.

\footnotetext{
O pensamento das ciências humanas nasce como pensamento sobre pensamentos dos outros, sobre exposições de vontades, manifestações, expressões, signos atrás dos quais estão os deuses que se manifestam (a revelação) ou os homens (as leis dos soberanos do poder, os legados dos ancestrais, as sentenças e enigmas anônimos, etc.) [...] estamos interessados na especificidade do pensamento das ciências humanas, voltado para pensamentos, sentidos e significados dos outros, etc., realizados e dados ao pesquisador apenas sobre a forma de texto. (BAKHTIN, 2010 [1973], p. 308)
}

Vale advertir que a acepção de "texto" no arcabouço teórico dado equivale à materialização de enunciados.

\footnotetext{
Essa acepção justifica o fato de Bakhtin apontar que a própria atitude humana é um texto em potencial, podendo ser compreendida (como atitude humana e não como ação física) unicamente no contexto dialógico da própria época (como réplica, como posição semântica, como sistema de motivos) (BAKHTIN, 2010 [1973], p. 312). Essa compreensão do fenômeno textual gera implicações que vão desde a abordagem que se deve tomar para seu estudo, passando pelos elementos que devem ser considerados nesse, até o papel e a relação do pesquisador no contexto da pesquisa fundamentais para o entendimento da perspectiva que o Círculo toma em relação às pesquisas em ciências humanas. (MENDONÇA, 2004, p.44)
}

Todas essas considerações reverberam na atitude e no papel do pesquisador diante de seu objeto de pesquisa. No caso desta pesquisa, o objeto (pintura artística) é assumido como 
texto que materializa o enunciado de quem o produziu e como enunciado lançado, portanto, constrói-se de valores ideológicos e pressupõe uma contra-resposta do pesquisador, razão pela qual este último figura como interlocutor que se predispõe a dialogar com ele.

A posição de interlocução do pesquisador, no entanto, é uma posição privilegiada porque extrapola os limites estabelecidos na relação dialógica do enunciado quando produzido. Em outras palavras, o pesquisador possui uma visão privilegiada do todo que engloba a enunciação materializada no objeto textual, podendo tecer as relações existentes entre os interlocutores envolvidos e os contextos imediato e mediato inerentes à sua produção. Decorre que a pesquisa corresponde

[...] a complexa inter-relação do texto (objeto de estudo e reflexão) e do contexto emoldurador a ser criado (que interroga, faz objeções, etc.), no qual se realiza o pensamento cognitivo e valorativo do cientista. É um encontro de dois textos - do texto pronto e do texto a ser criado, que reage; consequentemente, é o encontro de dois sujeitos, de dois autores. (BAKHTIN, 2010 [1973], p. 311)

Nesse encontro em que se constitui o fazer pesquisa em ciências humanas, o pesquisador, que possui uma posição exotópica privilegiada, deve orientar-se pelo seguinte direcionamento metodológico em relação ao enunciado:

$1^{\circ}$ ) Considerar a grande temporalidade (dimensão cronotópica mais ampla);

$2^{\circ}$ ) Considerar o contexto imediato de sua produção;

$3^{\circ}$ ) Considerar os interlocutores envolvidos;

$4^{\circ}$ ) Análise da materialidade discursiva do texto (enunciado).

A grande temporalidade ou dimensão cronotópica mais ampla consiste no recorte histórico-temporal maior que o engloba, a recuperação da historicização social a que pertence, o resgate histórico do contexto social em que se insere; o contexto imediato engloba todos os elementos que constituem o momento e o local (a esfera de atividade) de produção e, finalmente, os interlocutores constituem o sujeito/autor e os sujeitos aos quais se direcionam ou que terão contato com a obra produzida, todos aqueles a quem direta ou indiretamente se dirige a enunciação.

Compreendidas as etapas metodológicas, esclarecemos os trajetos de análise percorridos na pesquisa:

$1^{\circ}$ ) A grande temporalidade engloba a dimensão histórica atual do país, seu contexto político, social, econômico e cultural; 
$2^{\circ}$ ) O contexto imediato de produção compreende a Casa da Cultura em Parintins, representando a esfera de atividade, e as relações dialógicas constituídas em seu interior;

$3^{\circ}$ ) Os interlocutores envolvidos considerados foram o autor da obra, os sujeitos que circulam na Casa da Cultura ou que passam por ela, estando aptos a observar as obras nela registradas, e os sujeitos referidos na obra analisada;

$4^{\circ}$ ) A análise da materialidade discursiva, etapa final, consiste na análise da própria obra de arte, em diálogo com os achados das etapas anteriores.

Importa esclarecer que, em virtude das restrições impostas por este gênero discursivo, não apresentaremos com maior adentramento as análises detalhadas empreendidas em todas as etapas. Neste artigo, apontaremos as informações pertinentes mais gerais das três primeiras etapas necessárias à compreensão da materialidade discursiva enunciada na obra de arte, sobre a qual ater-nos-emos com maior atenção.

\section{Brasil: a grande temporalidade}

No eixo dos acontecimentos atuais que envolvem os escândalos de corrupção na política, na justiça e em outros segmentos no país, podemos afirmar que o Brasil de hoje enfrenta grave crise social, ética e ideológica. O espetáculo que ocupa as manchetes diariamente denuncia o fosso político-econômico e moral que afeta praticamente todas as esferas de atividade em que circulam cotidianamente os cidadãos brasileiros.

No auge do mecanismo de corrupção dos sistemas político e jurídico do Brasil e de sua propagação nos meios de comunicação em massa, muitos resquícios consequentes desse cenário principal são silenciados pela mídia e a contrapartida desse silenciamento aparece registrada em expressões locais que reivindicam, por meio da arte, da literatura ou de outros artifícios ideológicos sua representação, a divulgação de seu posicionamento, marcando, de algum modo, a participação social de sujeitos pertencentes a espaços sociais esquecidos ou rejeitados.

Podemos afirmar que a grande temporalidade que engloba o contexto de produção da obra tomada para análise equivale à própria história de constituição da nação brasileira. Por razões óbvias e já justificada alhures, não retomaremos esse percurso histórico, apenas apontamos a relevância de sua consideração como parte de um olhar amplo, global, completo ou, para utilizar um termo bakhtiniano, arquitetônico. 
No esteio desses acontecimentos sociais, Parintins, cidade interiorana do Amazonas, constitui-se como contexto imediato onde se insere a esfera de atividade em que é produzida a obra analisada, a esfera artística (e intelectual) representada na Casa de Cultura de Parintins, local em que se encontra materializado o enunciado, objeto de análise da pesquisa apresentada.

A apreensão dos enunciados pressupõe a apreensão prévia de seu contexto imediato e a apreensão das relações nele envolvidas. A compreensão da obra selecionada pressupõe, assim, o conhecimento da Casa de Cultura de Parintins e de seu significado para os cidadãos parintinenses.

\section{Casa de Cultura: contexto imediato}

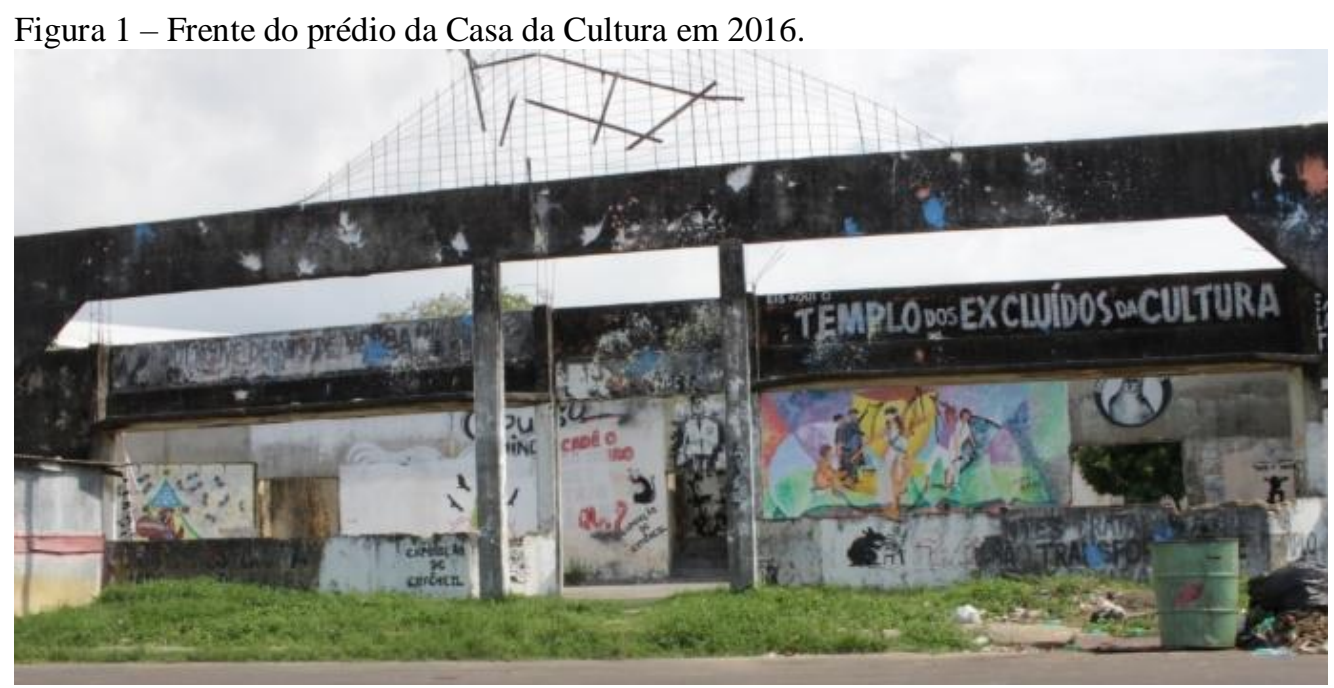

Fonte: Acervo da pesquisadora, 2016.

Conforme ilustra a fotografia acima, atualmente, a Casa da Cultura de Parintins corresponde a um prédio sem portas, sem janelas, sem piso, sem teto, com paredes quebradas e vigas de ferro à mostra. Apesar das condições estruturais precárias e de servir de abrigo a desocupados, esse espaço cultural mostra-se vivo pela atuação de grupos sociais, associações de artistas e universidades que realizam atividades públicas em prol da chamada de atenção da comunidade para a existência do prédio e de seu significado para o contexto social local. Exemplos dessas ações são $o$ Sarau realizado pelo Curso de Licenciatura em História da Universidade do Estado do Amazonas, em 2004; a realização do Abraço Simbólico pela União Nacional dos Estudantes (UNE), ocorrido em 2005 e a ocupação do Movimento Parintins Sem Fantasia, de 2013 até 2016 (do qual participou ativamente uma das pesquisadoras). 
O local figura como exemplo da desvalorização do patrimônio histórico material na cidade por parte do governo local, mas, também, destaca-se pela resistência social marcada pelo fluxo constante de atividades, dentre elas, as intervenções visuais. A entrada do prédio é marcada por grafites, pichações, colagens, murais, poemas, frases de incentivo à vida, denúncias e declarações de amor, conforme mostra a Figura 1. São formas de comunicar, de produzir linguagem, de registrar fatos, de gerar memórias, de materializar críticas e de concretizar manifestações sociais.

A reflexão que emerge recai sobre a intervenção visual urbana como um discurso construído pela coletividade, de modo a existir uma influência interna e externa à delimitação do espaço físico cultural, em que o jogo de forças configura tensão e abertura nesta produção demarcada pelas relações sociais construídas por um coletivo de sujeitos muitas vezes não identificados (ou identificados por um codinome artístico), mas, cujas vozes dialogam, através da expressão artística de questões que lhes são comuns, para a construção de um discurso político e social convergente.

A heterogeneidade do público levou-nos à identificação de movimentos sociais intitulados Parintins sem Fantasia, do qual participam membros dos seguintes grupos: Articulação Parintins Cidadão, Marcha Mundial das Mulheres, Movimento, Articulação Nacional de Educação Popular e Saúde, Jornal Plantão Popular, Instituto IRAPAM, Associação dos Artistas Plásticos do município, discentes e professores da Universidade Federal do Amazonas (UFAM), Universidade Estadual do Amazonas (UEA), Instituto Federal do Amazonas (IFAM), representantes da rede estadual de ensino local, movimentos de tribos urbanas como anarcopunk, hip hop, rock, para citar alguns.

No recorte realizado neste artigo, selecionamos a obra ilustrada na Figura 2, apresentada na próxima seção, resultado do concurso de painéis intitulado Natal sem Fantasia, evento cujo mote foi sensibilizar a comunidade através das artes plásticas para a construção de um sentido humano e realístico do natal parintinense, em contraposição aos esbanjamentos de dinheiro público na Praça da Liberdade.

Foram realizadas 21 inscrições para a produção das expressões artísticas que deveriam obedecer a critérios utilizados para avaliação, sendo: expressividade técnica e artística, Adequação e Coerência ao Tema, Originalidade, Criatividade, Harmonia, além da Crítica e da observância do tempo limite de 8 horas para a produção da arte. 
O tema sobre o qual foram produzidos os painéis corresponde a uma reação popular à terceira edição consecutiva da construção do Complexo Natalino em Parintins promovida com dinheiro público. O painel representa, assim, a contra- resposta política enunciada pelo autor às ações governamentais empreendidas na cidade, reforçando a noção da cidade como bem social, reconstruída simbolicamente, por meio da arte em desenho abstrato, corroborando com a afirmação de que "O desenho abstrato (...) é uma elaboração artística com valores e não só informativos" (SILVA, 2001, p. 5).

A imagem produzida dentro de um contexto social consiste em uma composição subjetiva, resulta em um signo, um todo composicional. "A conversão da imagem em símbolo a reveste de profundidade semântica" (BAKHTIN, 2011, p. 398). Sob esta perspectiva apreendemos o painel como intervenção urbana que se constitui como um enunciado.

\section{Os sujeitos interlocutores previstos e imediatos}

À apreensão de um texto ancorada na análise dialógica bakhtiniana, faz-se imprescindível a consideração dos sujeitos envolvidos na sua produção discursiva, conforme afirma Sobral:

[...] como não se pode entender o discurso sem entender seus sujeitos ou protagonistas, uma definição de discurso que não envolva uma definição dos sujeitos discursivos levando em conta seu ser socioistórico concreto e sua constituição no próprio discurso é incompleta.” (SOBRAL, 2009, p. 102)

Tal requisito deriva da própria condição dialógica do enunciado (e de sua enunciação), pois sua elaboração decorre das próprias relações interacionais e, portanto, sociais, existentes entre o sujeito que enuncia, seu (seus) destinatário(s) e aquele (s) que compõe(m) o conteúdo temático da enunciação, que podem equivaler, ou não, ao interlocutor direto ou imediato. Isso porque

A enunciação realizada é como uma ilha emergindo de um oceano sem limites, o discurso interior. As dimensões e as formas dessa ilha são determinadas pela situação da enunciação e por seu auditório. A situação e o auditório obrigam o discurso interior a realizar-se em uma expressão exterior definida, que se insere diretamente no contexto não verbalizado da vida corrente, e nele se amplia pela 
Todo texto verbal ou não-verbal, artístico ou não, imprime em si os sentidos derivados do projeto discursivo de seu enunciatário e do auditório ao qual se dirige. É, portanto, marcado pela especificidade temática e axiológica derivada da relação entre esses sujeitos sociais e de suas inserções na infraestrutura social. A ligação intrínseca entre os autores envolvidos e o conteúdo temático-axiológico enunciado faz com que os sujeitos do processo interacional componham, necessariamente, a apreensão do texto.

Em nosso contexto de pesquisa, os sujeitos envolvidos são o autor e os "leitores" de sua arte, que correspondem a cidadãos da cidade de Parintins que têm acesso às obras produzidas na Casa da Cultura de Parintins, bem como as figuras políticas atuantes no cenário social desta cidade, que aparecem retratados discursivamente no enunciado pintado. O auditório específico encerra, assim, os sujeitos que compartilham da situação socioeconômica e política delimitada geograficamente pela demarcação territorial que equivale a essa cidade amazônica. São, em última instância, os sujeitos a quem se dirige a obra e que aparecem contemplados na materialidade discursiva desta, mas não do mesmo modo.

Enquanto intervenção política, o painel é produzido por um sujeito de cidadania paritinense e dirigido aos seus conterrâneos que aparecem revozeados na crítica produzida, mas, também, às figuras políticas às quais a crítica é direcionada como contra-resposta às ações empreendidas pela esfera de atividade que representam. Essas correlações emergem com bastante nitidez na obra, como se pode apreender no processo de análise, a seguir.

\section{A intervenção artística urbana como enunciado}

Figura 2 - Painel $O$ Natal dos sonhos deles. 


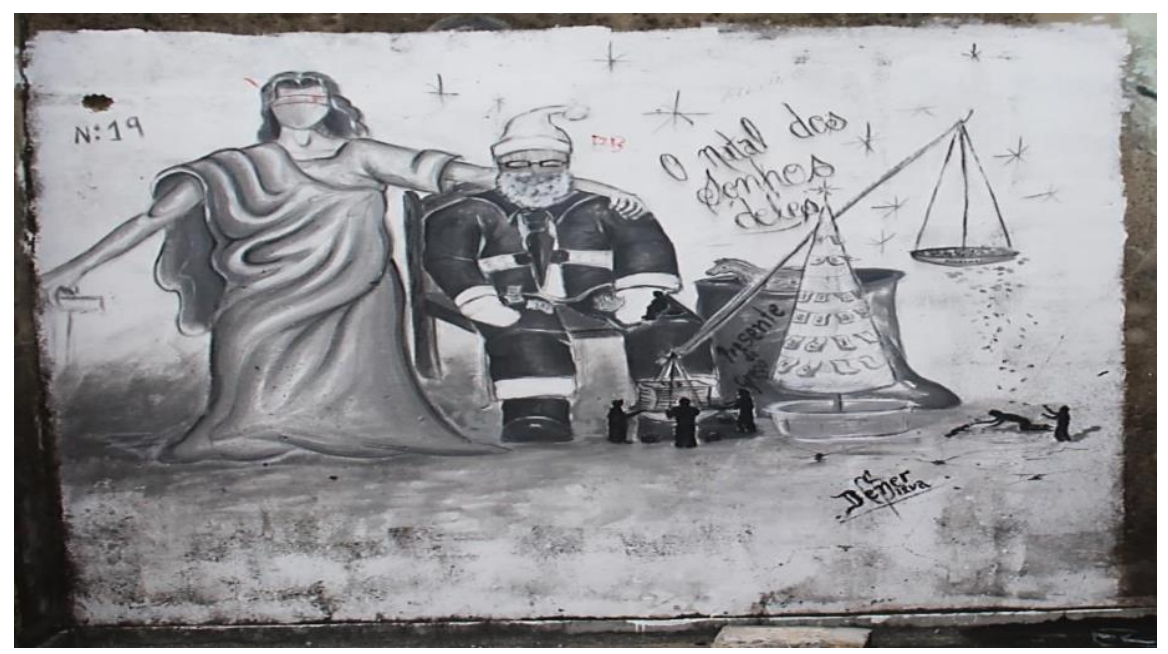

Fonte: Acervo de fotos da pesquisadora, 2015.

Antes de apresentar a análise do painel, vale ressaltar a especificidade de sua dimensão textual e as interferências dessa especificidade no processo de leitura. Como obra de arte multimodal, a materialidade da tessitura textual decorre de relações semânticas, referenciais e, portanto, coesivas que se distinguem das relações empreendidas no texto exclusivamente verbal, pois os elementos referenciados, retomados e ressignificados, são construídos discursivamente, por meio das relações de coesão que se estabelecem entre os elementos verbais e não-verbais que o constituem, de modo a dar conta da construção do projeto enunciativo do autor de maneira coerente.

A definição multimodal corresponde ao aspecto híbrido de textos formados por signos de natureza distintas. Enquanto a materialidade dos textos verbais é constituída apenas pelos signos linguísticos e a materialidade de textos imagéticos é constituída apenas por imagens, a materialidade do painel em questão constitui-se pela conjunção desses dois modos de representação, daí a necessidade de se considerar sua multimodalidade e a hibridização dos elementos que a compõem.

Todos esses aspectos compreendem o domínio de sua dimensão textual. Há que se considerar que, segundo a orientação metodológica dialógica, a apreensão do todo discursivo que o painel representa enquanto enunciado concreto exige de nós, interlocutores, a conjugação da dimensão textual que encerra o gênero do discurso em que se materializa (e seus respectivos elementos constitutivos ) com a dimensão social (contemplada nas seções anteriores: a grande temporalidade, o contexto imediato de sua produção; a esfera de atividade os interlocutores envolvidos) que fomentou sua produção. 
Em razão das peculiaridades de cada esfera, definem-se os modos de dizer autorizados nela e por ela legitimados, por isso, Bakhtin definiu o gênero como tipo relativamente estável (BAKHTIN, 2011, p.262), ou seja, formas pré-estabelecidas de uso da linguagem (verbal e/ou não verbal) que se concretizam por meio do conteúdo temático, do estilo e da construção composicional.

O conteúdo temático equivale ao aspecto discursivo do enunciado composto pela congruência dos elementos linguísticos e extralinguísticos, apresentando-se "como a expressão de uma situação histórica concreta que deu origem à enunciação" (BAKHTIN/VOLOCHINOV, 2009[1929], p. 133), enquanto o estilo corresponde às escolhas linguísticas e discursivas do autor em função de sua intenção enunciativa e "diz respeito às possibilidades de utilização dos recursos linguísticos e multimodais, de modo que concretizemos nosso projeto de dizer" (COSTA-HÜBES, 2014, p. 25). Já a construção composicional equivale ao aspecto multimodal já elucidado, à estrutura material que compõe a obra.

Coadunando com esse arcabouço teórico, tomamos o painel apresentado nas Figuras 2 e 3 como um gênero discursivo próprio do campo da produção artística visual urbana, produzido por um autor-artista, materializado em uma parede de livre acesso público e aberto a contrarespostas dos interlocutores que circulam no local, ou seja, passível de ser apreciado por inúmeros destinatários previstos, os quais construirão significados sobre o mesmo, passando a dialogar com ele e a formar posicionamentos sobre os sentidos e os efeitos dos sentidos suscitados pelo seu enunciado. Isso significa que, enquanto texto-enunciado híbrido, o painel produzido no campo/esfera de atividade artística urbana concretiza-se, também, a partir das vozes de seus interlocutores/destinatários que tomarão como enunciado concreto a inteireza de seu plano de expressão.

Deste modo, o painel corresponde a um enunciado, porque os enunciados equivalem a unidades reais de comunicação (FIORIN, 2006, p.20), independentemente de sua extensão. E, como todo enunciado, resulta de prática concreta e efetiva da linguagem, constitui-se dialogicamente, correspondendo a um discurso vivo que deve ser considerado em seu contexto real e historicamente situado no âmbito da esfera de atividade em que se apresenta.

Neste sentido, o discurso materializado no painel traça relações internas (num único quadro), entre as demais intervenções vistas no prédio (com as demais artes), com os discursos interiorizados de seus autores e também com os de seus interlocutores. O entremeado dessas relações corresponde à ideia bakhtiniana de dialogismo como um processo de interlocução entre 
enunciados, os quais podem estar apresentados em discursos verbais ou não-verbais, produzidos no campo da comunicação e permeados de vozes de outrem.

\begin{abstract}
Enquanto conjunto e sob a perspectiva dialógica, o enunciado/texto verbo-visual caracteriza-se como dimensão enunciativo-discursiva reveladora de autoria (individual ou coletiva), de diferentes tipos de interlocuções, de discursos, evidenciando relações mais ou menos tensas, entretecidas pelo face a face promovido entre verbal e visual, os quais se apresentam como alteridades que, ao se defrontarem, convocam memórias de sujeitos e de objetos, promovendo novas identidades (BRAIT, 2003, p. 62).
\end{abstract}

Em consonância com essa perspectiva, a análise do painel aqui apreendida seguirá a descrição de seu conteúdo mediada por cada um dos elementos supramencionados, para dar conta da relação entre a situação real de interação e sua emolduração pelo gênero do discurso dentro da esfera de atividade humana em que se concretiza. Esta opção justifica-se pelo fato de os gêneros corresponderem a práticas sociais, através das quais os sujeitos situados historicamente estabelecem entre si relações dialógicas específicas das esferas de atividades em que circulam. Tecidas todas essas considerações necessárias, apresentamos, na sequência, a sistematização das apreensões sobre a intervenção artística, objeto da pesquisa.

O painel O Natal dos Sonhos deles foi produzido na Casa da Cultura Alzira Saunier, durante a realização de um concurso de painéis com o tema Natal sem Fantasia, em 19 de dezembro de 2015. Esse concurso foi promovido pelo movimento popular Parintins Sem Fantasia que realiza ocupações não-periódicas no prédio da Casa da Cultura desde 2013. Assume-se que o Movimento realiza ocupações, pois o espaço cultural mencionado encontrase em estado de abandono desde 1992, sendo um projeto inacabado do ponto de vista do património material. Embora tenha sido um prédio idealizado para que funcionasse como espaço para realização de cursos, lazer e outras atividades culturais, nunca chegou a exercer a função proposta devidamente, o que incitou o surgimento de questionamentos e a polêmica sobre o desvio da verba pública destinada à sua construção.

O painel O Natal dos sonhos deles é rico em detalhes (Figuras 2 e 3). É um painel que está assinado, mede cerca de 2 metros de largura e $2 \mathrm{~m} 50 \mathrm{~cm}$ de altura, foi produzido com tinta à base d'agua e pinceis. É um dos poucos que tem algum tipo de rabisco, intervenção externa percebida após seis meses de produção da data em que foi fotografado, mas são rabiscos aleatórios (em vermelho), que ainda não comprometem o entendimento da mensagem. 
A elaboração de seu tecido textual dá-se por meio da retomada de vários referentes culturais e históricos que ultrapassam os limites da realidade local de Parintins, por meio da ressignificação de signos ideológicos através de uma intertextualidade híbrida construída pelo atravessamento de componentes imagéticos e verbais que dialogam, no interior do próprio enunciado-painel, dando origem à sua dimensão discursiva. Detalharemos, no quadro a seguir, os elementos textuais- discursivos agenciados. Reapresentaremos antes, porém, a obra focalizada de maneira a viabilizar melhor visualização dos elementos descritos na tabela.

Figura 3- Detalhe do painel

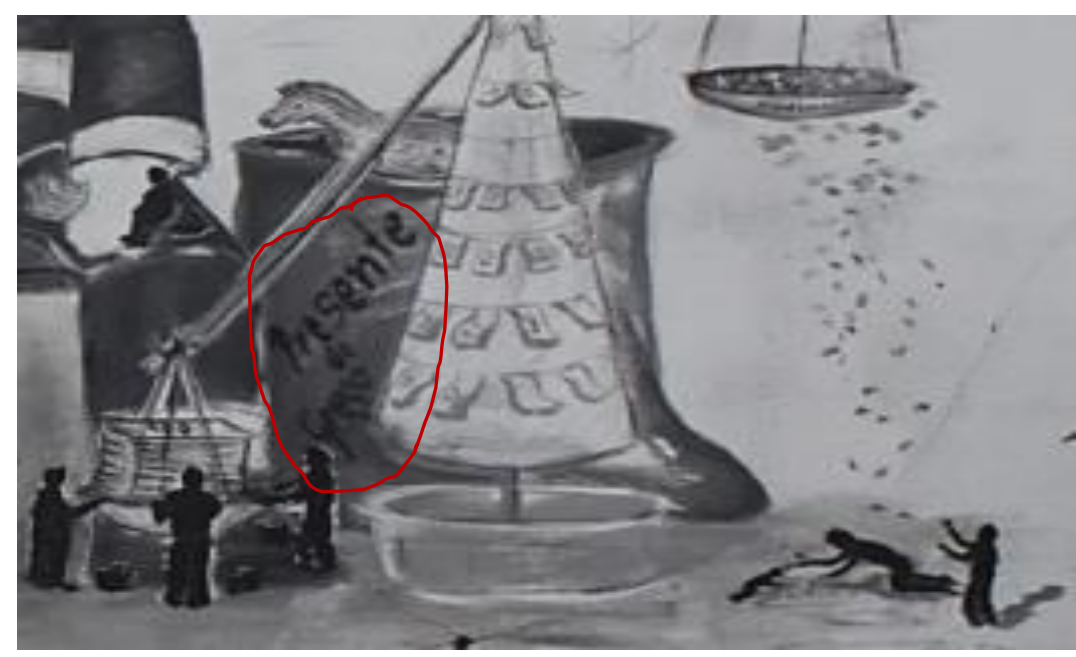

Fonte: Recorte da figura 02

Tabela dos elementos discursivizados

\begin{tabular}{|c|c|c|c|c|}
\hline SIGNO & ORIGEM & $\begin{array}{l}\text { CONTEXTO } \\
\text { INICIAL }\end{array}$ & \multicolumn{2}{|c|}{$\begin{array}{l}\text { EXTENSÕES DE SENTIDO / } \\
\text { RESSIGNIFICADO }\end{array}$} \\
\hline Justiça & $\begin{array}{l}\text { Mitologia Romana } \\
\text { (Justitia) } \\
\text { Mitologia Grega } \\
\text { (Deusa Dice) }\end{array}$ & $\begin{array}{l}\text { Dice, da mitologia } \\
\text { grega, filha de } \\
\text { Têmis, corresponde } \\
\text { a uma } \\
\text { representação } \\
\text { primordial do } \\
\text { conceito de lei, } \\
\text { ligada ao } \\
\text { juramento dos } \\
\text { homens e lei. Em } \\
\text { sua versão } \\
\text { original, não } \\
\text { empunha uma } \\
\text { espada. Equivale } \\
\text { ao conceito mais } \\
\text { evoluído quanto à } \\
\text { lei e à ordem. } \\
\text { Justitia possui os } \\
\text { olhos vendados, }\end{array}$ & $\begin{array}{l}\text { O que a mitologia } \\
\text { romana pretende } \\
\text { alcançar é uma } \\
\text { sabedoria por meio do } \\
\text { equilíbrio entre a } \\
\text { idealização e a prática. } \\
\text { Mas a complexidade } \\
\text { está no conceito de } \\
\text { justiça apresentar } \\
\text { diferenciações que } \\
\text { nem sempre } \\
\text { favorecem a justiça, } \\
\text { efetivamente. } \\
\text { As representações da } \\
\text { cosmogonia grega não } \\
\text { são do domínio } \\
\text { material, como } \\
\text { podemos nos remeter }\end{array}$ & $\begin{array}{l}\text { A justiça não está } \\
\text { representada como justa. } \\
\text { O fiel que equilibra a } \\
\text { balança é representado } \\
\text { pela Árvore de Natal, a } \\
\text { qual pende os pratos de } \\
\text { modo desigual. A espada } \\
\text { continua em repouso, } \\
\text { portanto não será usada } \\
\text { para fazer valer a lei. Os } \\
\text { olhos da imagem estão } \\
\text { vendados, pois é uma } \\
\text { forma de manter a } \\
\text { imparcialidade, sem } \\
\text { conhecer a diferença na } \\
\text { diferença para alcançar a } \\
\text { verdade. }\end{array}$ \\
\hline
\end{tabular}




\begin{tabular}{|c|c|c|c|c|}
\hline & & $\begin{array}{l}\text { bem como mantém } \\
\text { uma espada em } \\
\text { posição de repouso } \\
\text { (para usar em } \\
\text { combate apenas se } \\
\text { necessário), além } \\
\text { da balança que fica } \\
\text { suspensa e possui } \\
\text { o fiel (indicador do } \\
\text { equilíbrio). }\end{array}$ & $\begin{array}{l}\text { primeiramente. Elas } \\
\text { são, na verdade, no } \\
\text { sentido conceitual. O } \\
\text { que nos leva a } \\
\text { questionar: Mas o que } \\
\text { os gregos queriam } \\
\text { dizer com tais } \\
\text { narrativas? No caso da } \\
\text { relação entre Têmis e } \\
\text { Zeus, que nenhum } \\
\text { bom líder toma } \\
\text { decisão sem antes } \\
\text { ouvir. }\end{array}$ & $\begin{array}{l}\text { No caso do painel, a } \\
\text { crítica é de que a Justiça } \\
\text { pode estar de um lado (o } \\
\text { da esfera política), } \\
\text { ignorando o outro lado (o } \\
\text { povo local) mais sofrido. }\end{array}$ \\
\hline $\begin{array}{l}\text { Árvore } \\
\text { de Natal }\end{array}$ & $\begin{array}{l}\text { Supostamente surgida } \\
\text { por volta de } 1500 \text {, na } \\
\text { Alemanha, com } \\
\text { Martinho Lutero. }\end{array}$ & $\begin{array}{l}\text { Representa hoje } \\
\text { um dos maiores } \\
\text { símbolos do Natal, } \\
\text { sobretudo na } \\
\text { civilização } \\
\text { ocidental cristã. } \\
\text { Vincula-se ao } \\
\text { divino e à vida. }\end{array}$ & $\begin{array}{l}\text { No painel, faz } \\
\text { referência à } \\
\text { construção de uma } \\
\text { árvore maior que a } \\
\text { dos anos anteriores, } \\
\text { com } 36 \text { metros de } \\
\text { altura, podendo } \\
\text { configurar o grande } \\
\text { presente de grego } \\
\text { dado à população de } \\
\text { Parintins, ao passo } \\
\text { que a balança da } \\
\text { justiça desiquilibra a } \\
\text { igualdade e tomba } \\
\text { mais para "Os sonhos } \\
\text { deles". }\end{array}$ & $\begin{array}{l}\text { No contexto da cidade de } \\
\text { Parintins representa a } \\
\text { inescrupulosidade dos } \\
\text { representantes políticos } \\
\text { locais e a negligência } \\
\text { desses mesmos } \\
\text { representantes em relação } \\
\text { às necessidades } \\
\text { emergentes da sociedade e } \\
\text { da cidade de Parintins, } \\
\text { tendo, por extensão, sido } \\
\text { tomado como símbolo da } \\
\text { política local. }\end{array}$ \\
\hline $\begin{array}{l}\text { Papai- } \\
\text { Noel }\end{array}$ & $\begin{array}{l}\text { De acordo com a } \\
\text { lenda, São Nicolau era } \\
\text { um bispo nórdico que } \\
\text { tinha o hábito de } \\
\text { ajudar as pessoas } \\
\text { pobres. A figura } \\
\text { emblemática atual foi } \\
\text { criada pelo alemão } \\
\text { Thomas Nast, em } \\
\text { 1866 e sua } \\
\text { popularidade mundial } \\
\text { expandiu-se em } \\
\text { função do marketing } \\
\text { da empresa Coca- } \\
\text { Cola, que lançou uma } \\
\text { campanha publicitária } \\
\text { em 1931 utilizando a } \\
\text { imagem criada por } \\
\text { Nast. }{ }^{3}\end{array}$ & $\begin{array}{l}\text { Simboliza o Natal, } \\
\text { sobretudo na } \\
\text { acepção tomada no } \\
\text { mundo ocidental. }\end{array}$ & $\begin{array}{l}\text { A representação da } \\
\text { figura do Natal } \\
\text { também está com } \\
\text { cédulas de dinheiro na } \\
\text { mão, e usa gravata e } \\
\text { paletó, como uma } \\
\text { figura política, } \\
\text { desconstruindo sua } \\
\text { acepção comum. }\end{array}$ & $\begin{array}{l}\text { A deusa em pé, ao lado da } \\
\text { representação do Papai } \\
\text { Noel "político" denota o } \\
\text { desequilíbrio da balança à } \\
\text { favor da esfera política, } \\
\text { em detrimento da } \\
\text { população. }\end{array}$ \\
\hline Balança & $\begin{array}{l}\text { Mitologia Romana } \\
\text { (Compõem a imagem } \\
\text { da Justitia, ) }\end{array}$ & $\begin{array}{l}\text { Símbolo da } \\
\text { equidade; justiça. }\end{array}$ & $\begin{array}{l}\text { A balança está longe, } \\
\text { em uso por grupos } \\
\text { pequenos, com acesso } \\
\text { a muito dinheiro, o } \\
\text { que desiquilibra a }\end{array}$ & $\begin{array}{l}\text { O quadro descrito } \\
\text { denuncia a inexistência da } \\
\text { justiça e da igualdade no } \\
\text { contexto representado. } \\
\text { Existe um grande }\end{array}$ \\
\hline
\end{tabular}

\footnotetext{
${ }^{3}$ Fonte: https://www.significados.com.br/papai-noel/
} 


\begin{tabular}{|l|l|l|l|l|}
\hline & & & $\begin{array}{l}\text { balança e deixa que } \\
\text { apenas restos sejam } \\
\text { lançados para algumas } \\
\text { personagens } \\
\text { desenhadas em } \\
\text { posição de súplica e } \\
\text { ajoelhadas sobre o } \\
\text { chão. }\end{array}$ & $\begin{array}{l}\text { desiquilíbrio representado } \\
\text { imageticamente e o lado } \\
\text { para o qual tomba a } \\
\text { balança denota que a } \\
\text { esfera jurídica está ao } \\
\text { lado da esfera política } \\
\text { causando o desequilíbrio } \\
\text { delatado. }\end{array}$ \\
\hline $\begin{array}{l}\text { Presente } \\
\text { de } \\
\text { Grego }\end{array}$ & $\begin{array}{l}\text { Literatura Grega: } \\
\text { Guerra de Tróia }\end{array}$ & $\begin{array}{l}\text { Representa a } \\
\text { armadilha grega } \\
\text { para vencer a } \\
\text { guerra dos troianos }\end{array}$ & $\begin{array}{l}\text { Sua extensão de } \\
\text { sentido, bastante } \\
\text { recorrente na } \\
\text { atualidade o equipara } \\
\text { à surpresas } \\
\text { indesejáveis, de mal } \\
\text { tom, de valoração } \\
\text { negativa. }\end{array}$ & $\begin{array}{l}\text { Associado ao saco do } \\
\text { Papai Noel, na obra, faz } \\
\text { referência à comemoração } \\
\text { natalina financiada pelo } \\
\text { governo de Parintins. }\end{array}$ \\
\end{tabular}

Fonte: Elaborado pela autora, 2018.

Como se pode verificar, por meio das referências descritas na tabela, a obra de arte analisada constitui-se, efetivamente, como enunciado concreto, integrando os elementos composicional, temático e estilístico próprios do gênero painel no qual se materializa. Além disso, constitui-se discursivamente como contra-resposta dirigida a destinatários previstos e localizados, cronotopicamente, no espaço-tempo que corresponde à Parintins atual e, para isso, dialoga com o contexto específico dessa dimensão histórica. De modo que só se faz possível sua apreensão por meio do acionamento de seus elementos extratextuais e da dimensão social de onde deriva.

\section{Considerações Finais}

Para acabamento deste artigo, consideramos relevante retomar o complexo conceito dialógico e suas três camadas com dados da própria obra de arte analisada: a primeira, referese à constituição do enunciado, a partir de outros enunciados, pois cada enunciado é um elo na corrente complexamente organizada de outros enunciados (BAKHTIN, 2011, p. 272). Sabe-se que o painel foi construído com um determinado objetivo, como resposta a outros discursos, especialmente em relação à construção do complexo natalino em um momento de marcada restrição econômica da cidade, portanto, seu posicionamento critico revela-se nos traços da arte como resposta a ser compreendida.

Quanto à segunda camada conceitual de dialogismo, tomamos o dialogismo em seu aspecto composicional, observado via incorporação, pelo enunciador, da voz ou das vozes de 
outro(s), no caso do painel, perceptível por meio da utilização metafórica de alegorias que retomam conceitos ideológicos prévios, como o símbolo da justiça e o simbolismo do Natal, bem como a mitologia grega, por meio da intertextualidade.

Finalmente, à terceira camada conceitual de dialogismo diz respeito à ideia de que a própria natureza social do indivíduo é dialógica, uma vez que a individualidade é definida e reforçada pela relação de alteridade com o(s) outro(s), por meio da linguagem. Deste modo, dialogismo equivale, também, a posicionamento (de concordância ou de discordância), valoração, resposta, compreensão ativa. Como o próprio título da obra O Natal dos Sonhos Deles ratifica, fazendo referência ao slogan da prefeitura Construindo a Parintins dos nossos sonhos, seu projeto enunciativo é dirigido axiologicamente enquanto resposta e datado sóciohistoricamente. Ademais, o enunciado completo que encerra o painel dialoga com textos, sentidos, signos que lhe precedem dialogicamente. Tal fato vai ao encontro do que explica Fiorin (2006):

Com a concepção dialógica da linguagem, a análise histórica de um texto deixa de ser a descrição da época em que o texto foi produzido e passa a ser uma fina e sutil análise semântica, que leva em conta confrontos sêmicos, deslizamentos de sentido, apagamento de significados, interincompreensões, etc. (FIORIN, 2006, p.191)

Coadunando com essa citação, fica evidente a existência de um pensamento crítico revelado discursivamente e da assunção da responsabilidade sobre a crítica enunciada. Assim, pondera-se que a dimensão visual proporciona a leitura sobre o processo que resulta no visível, mas não se esgota, sem antes refletir sobre o que pode estar implícito, como os elementos que constituem sua dimensão social.

A Casa da Cultura de Parintins apresenta-se, no escopo dessa dimensão social, como a materialidade de uma esfera de atividade humana ímpar em que se entrelaçam o artístico e o urbano, onde é possível apreender o enunciado do painel, cujo discurso vai além daquelas paredes, tendo entrado já na rede dialógica ad infinitum. Pode-se, portanto, afirmar que, mesmo que esta intervenção artística seja apagada de seu local de origem, ela já está no mundo enquanto voz discursiva que se abre a contra-respostas, como, a partir de sua retomada no âmbito desta pesquisa, por exemplo, passa a ser refletida e refratada gerando novos sentidos a cada nova relação dialógica.

\section{Referências}


BAKHTIN, Mikhail. Estética da criação verbal. 6ed. São Paulo, Martins Fontes. 2011. Estética da criação verbal. Trad. do russo por Paulo Bezerra. 5. ed. São Paulo: Martins Fontes, 2010 [1979].

; VOLOCHINOV, Valentin Nikolaevich. (1929). Marxismo e filosofia da linguagem. Tradução do francês por Michel Lahud e Yara F. Vieira. 13. ed. São Paulo: Hucitec, 2009.

BRAIT, Beth. Olhar e ler: verbo-visualidade em perspectiva dialógica. Bakhtiniana, São Paulo, vol. 8, n. 10, p. 43-66, jul - dez. 2013.

CIAVATTA, Maria; ALVES, Nilda (orgs.). A leitura de imagem na pesquisa social: história, comunicação e educação. São Paulo: Cortez, 2004.

COSTA-HÜBES, Terezinha da Conceição. Os gêneros discursivos como instrumentos para o ensino de Língua Portuguesa: perscrutando o método sociológico bakhtiniano como ancoragem para um encaminhamento didático-pedagógico. In: NASCIMENTO, Elvira Lopes do; ROJO, Roxane Helena Rodrigues. (Orgs.). Gêneros de Texto/Discurso e os desafios da contemporaneidade: São Paulo: Pontes Editora, 2014. p. 13-34

FIORIN, José Luiz. Introdução ao pensamento de Bakhtin. São Paulo: Ática, 2006.

Interdiscursividade e intertextualidade. In: BRAIT, Beth (Org.). Bakhtin: outros conceitos-chave. São Paulo: Contexto, 2010, p. 163 - 193.

JOLY, Martine. Introdução à análise da imagem. Campinas: Papirus, 1996.

MENDONÇA, Fernanda Dias de Los Rios. Discurso de professores de língua portuguesa em formação: uma análise dialógica de relatórios de estágio supervisionado de observação. 2014. 273 f. Tese (Doutorado em Linguística) - Programa de Pós-Graduação em Linguística, Universidade Federal de Santa Catarina, Florianópolis, 2014.

SILVA, Armando. Imaginários urbanos. São Paulo: Perspectiva; Bogotá (Colômbia), Convênio Andes Bello, 2001.

SOBRAL, Adail. Do dialogismo ao gênero: as bases do pensamento do círculo de Bakhtin. Série Ideias sobre Linguagem. São Paulo: Mercado de Letras, 2009.

Recebido em 31 de outubro de 2018. Aceito para publicação em 29 de novembro de 2018. 